\title{
ZAP - Muito mais que um acesso privilegiado
}

\section{Resumo}

Parafraseando as prescrições e especificações técnicas da $2^{\text {a }}$ Edição do Manual de Infraestruturas de Telecomunicações em Edifícios (ITED), "Os fogos de uso residencial possuem, obrigatoriamente, um local onde se concentram as três tecnologias: par de cobre (PC), cabo coaxial (CC) e fibra ótica (FO). Esse local é designado por Zona de Acesso Privilegiado (ZAP) e localiza-se na divisão mais adequada, no entendimento do projetista e de acordo com as preferências do dono de obra".

Nesta zona concentram-se as 3 tecnologias atualmente obrigatórias constituindo, assim, um suporte para o fornecimento avançado de serviços tecnológicos evoluídos.

A modernização e evolução das infraestruturas de comunicações eletrónicas em Portugal na última década, quer ao nível regulatório, quer ao nível tecnológico dos equipamentos, constituem, implacavelmente, um poderoso incentivo à expansão da sociedade do conhecimento que deixaremos como legado às gerações vindouras.

\section{Introdução}

A entrada em vigor do Manual ITED, 1a Edição, Julho de 2004, aplicou-se a todos os edifícios novos ou alvo de remodelação, a partir de 1 de Janeiro de 2005, e representou uma alteração profunda da filosofia do quadro regulatório do anterior Regulamento de Instalações Telefónicas de Assinante (RITA), de forma a ter em conta a evolução tecnológica das soluções de infraestrutura de rede a instalar nos edifícios, designadamente, par de cobre e cabo coaxial.

Com efeito, e no que respeita às redes de cabo coaxial, foram definidas as regras e especificações técnicas a cumprir para o estabelecimento de infraestruturas de receção de sinais sonoros e de vídeo. Assim, foram criadas as condições para a receção das redes de televisão por cabo (CATV), entretanto difundidas por Portugal, assim como as ligações efetuadas a partir das antenas hertzianas ou de satélite.
Testemunhamos uma revolução na oferta de um maior número de canais televisivos com qualidade crescente.

Aliás, a privatização do setor das telecomunicações foi a ignição necessária para o surgimento de novos serviços de telecomunicações. Assistimos a uma crescente procura de serviços com cada vez mais maior largura de banda.

O novo paradigma introduzido pela 1a Edição do Manual ITED abordou, ainda, a possibilidade de se implementarem redes de cablagem estruturada que consistia, basicamente, numa infraestrutura mista utilizada para comunicações de dados e de voz.

\section{ZAP - Zona de Acesso privilegiado}

Aquando da aplicação da 1a Edição do Manual ITED a colocação da ZAP na rede individual das frações autónomas residenciais era apenas recomendada. Recordando o ponto 4.3.5 do anterior Manual ITED: "Recomenda-se a existência de uma Zona de Acesso Privilegiado (ZAP). A ZAP caracterizase pela existência, no mesmo local, de 2 tomadas coaxiais a uma distância máxima de $30 \mathrm{~cm}$ uma da outra (preferencialmente integradas no mesmo espelho). Esta zona vai permitir a ligação simultânea, de um mesmo equipamento terminal de cliente, a dois sinais distintos provenientes de 2 redes coaxiais, estando assim preparada para futuros serviços baseados na tecnologia coaxial. A localização da ZAP fica ao critério do projetista".

A Figura 1 ilustra a representação em projeto e uma foto real de um exemplo típico de uma ZAP quando a 1a Edição do Manual ITED se encontrava em vigor.

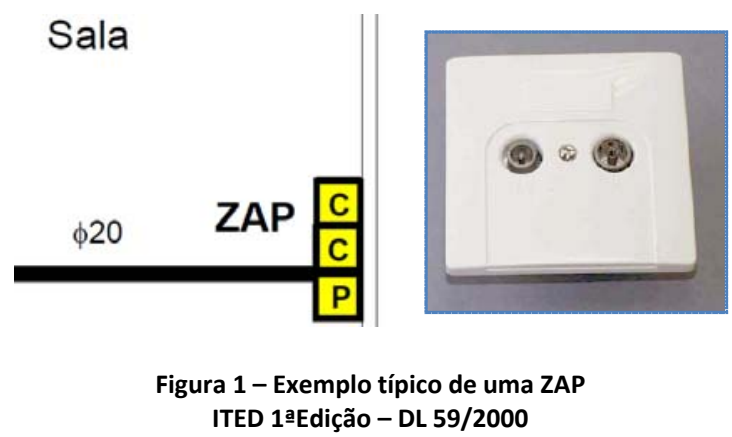


De notar que a instalação deste acesso privilegiado não se revestia de cariz obrigatório mas antes de uma recomendação que o projetista/dono de obra poderia, ou não, ter em linha de conta.

Passados apenas 4 anos da entrada em vigor da 1a Edição do Manual ITED, a Autoridade Nacional de Comunicações (ANACOM) edita a 2a Edição do Manual ITED.

Este novo Manual ITED não sendo um Manual de rutura relativamente ao primeiro é, ainda assim, muito inovador tanto em conceitos de infraestrutura como de equipamentos e respetivas especificações. Afirmar que a $2^{a}$ Edição do Manual ITED se relaciona apenas com a obrigação de instalar fibra ótica nos edifícios trata-se, seguramente, de uma afirmação muito redutora daquilo que representa na realidade a 2a Edição do Manual ITED.

Profundas foram as mudanças introduzidas no conceito de zona de acesso privilegiado. Conforme o ponto 8.1 da $2^{\mathrm{a}}$ Edição do Manual ITED poder-se-á ler que "os fogos de uso residencial possuem, obrigatoriamente, um local onde se concentram as três tecnologias ( $P C, C C$ e FO). Esse local é designado por Zona de Acesso Privilegiado (ZAP) e localiza-se na divisão mais adequada, no entendimento do projetista e de acordo com as preferências do dono da obra".
Assim, a instalação da ZAP passa de opcional/recomendada para obrigatória. Além disso, representa um ponto de convergência das 3 tecnologias atualmente usadas, conforme ilustrado na Figura 2.

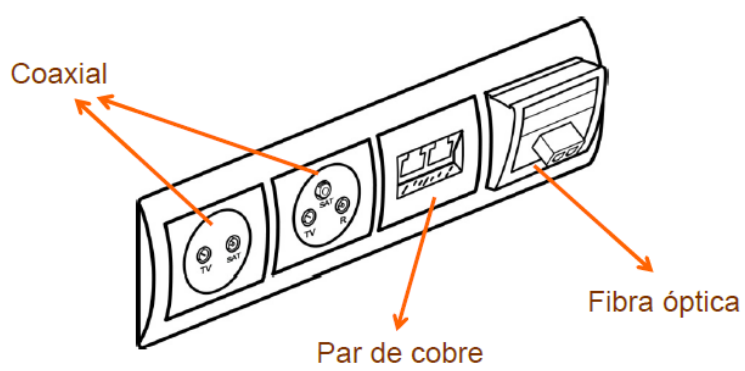

Figura 2 - Exemplo de uma tomada de uma ZAP (Fonte: ITED 2aEdição - Figura 109)

A Figura 3 representa os locais de colocação obrigatória da ZAP e das restantes tomadas (por cada diferente tecnologia). Conforme se poderá observar pela figura, e em função do local e tipo de tomadas, a industria desenvolveu produtos que dão resposta aos aspetos regulamentares introduzidos pela 2a Edição do Manual ITED.

A existência de duas tomadas por tecnologia permitirá, por exemplo, utilizar uma como ponto de receção de sinal, e outra de envio para o ponto de distribuição - Armário de Telecomunicações Individual (ATI).

\section{iTEd 2.a Ediçáo - MONTAGEM TÍPICA}

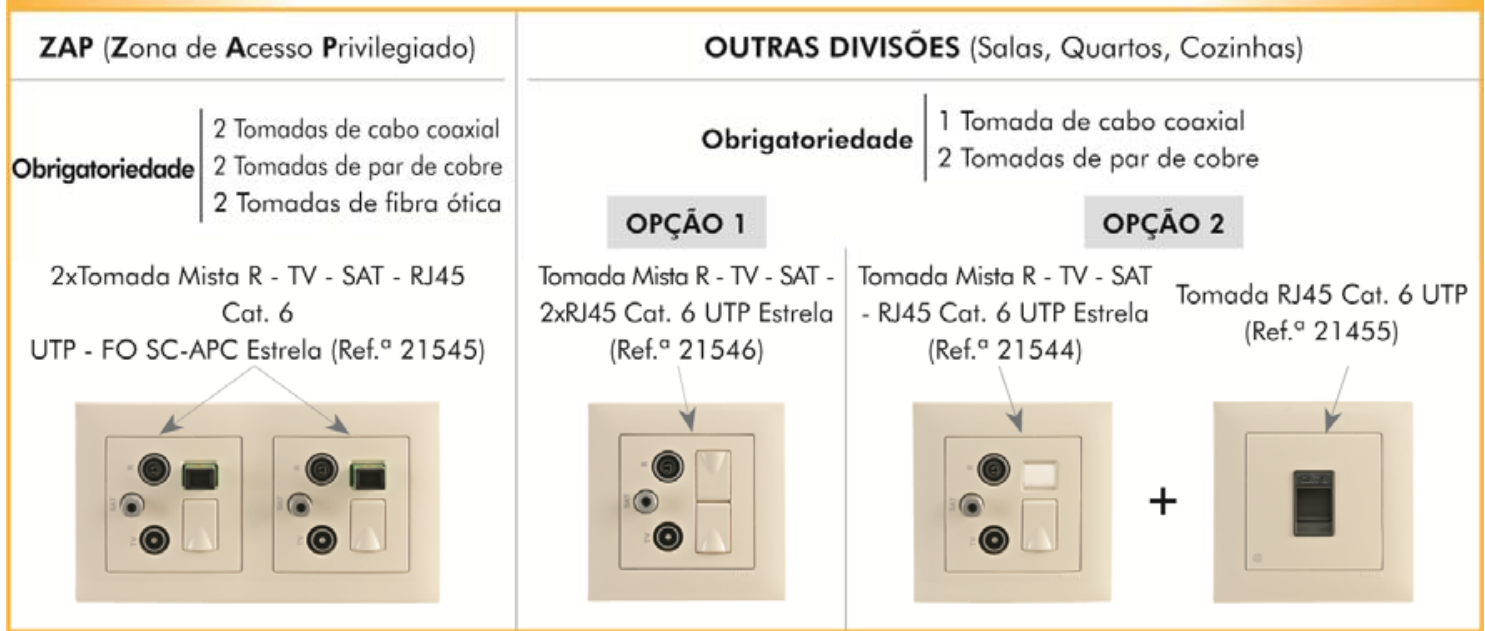

Figura 3 - Locais de colocação obrigatória de tomadas na rede individual 
A Figura 4 representa um exemplo das potencialidade de utilização da ZAP. Assim, é ilustrada a possível utilização de um serviço prestado por um determinado operador, neste caso em tecnologia de fibra ótica, que é ligada desde o secundário do repartidor de cliente alojado no (ATI) até à tomada de FO da ZAP. Aqui, um conversor eletro-ótico (ONT - Optical Network Terminal), receciona o sinal do operador e distribui novamente ao ATI via par de cobre, disponibilizando assim, este serviço pelas restantes divisões da fração.

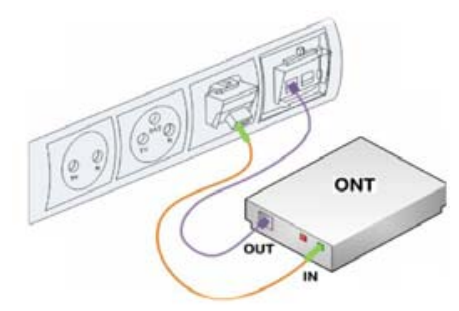

Figura 4 - Exemplo de ponto de receção e envio de sinal na ZAP

Com efeito, e com o estabelecimento destas novas infraestruturas os operadores são agora capazes de assegurar serviços com maior largura de banda.

\section{Obstáculos à mudança}

As prescrições técnicas da 2a Edição do Manual ITED vem, definitivamente, em defesa dos interesses dos consumidores de comunicações eletrónicas. Essa defesa de interessa passa, impreterivelmente, por infraestruturas de telecomunicações modernas, fiáveis e adaptadas aos serviços dos operadores .

Mas, e em abono da verdade, estas prescrições técnicas asseguram que todos os edifícios (novos ou alvo de remodelação) terão, forçosamente, de estar adaptados às exigências especificadas no Manual ITED. Desta forma, e independentemente de quem possa, a dado momento, usufruir das instalações, estas garantem o suporte de receção das comunicações eletrónicas.

Apesar desta obrigatoriedade legislativa (a aplicação da infraestruturas de telecomunicações em edifícios), muitos são, infelizmente, os casos de relutância que se vão observando por parte dos donos de obra em executar tais infraestruturas, refugiando-se no fundamento que irão habitar/usar as instalações que construem para todo o sempre e que "jamais" irão necessitar de uma infraestrutura de telecomunicações em conformidade com a legislação vigente.

A História, ensina-nos precisamente o contrário. Se numa dada realidade apenas nos "faz falta o que conhecemos e não o que desconhecemos", temos presenciado que vivemos na era das comunicações e da informática. A tecnologia evolui a um ritmo acelerado e extremamente dinâmico. Quem, há cerca de 15/20 anos diria que cada pessoa com mais de 16 anos em Portugal teria um telemóvel, senão mais que um? Quem diria que a utilização generalizada da internet seria uma realidade, quando apenas estava franqueada ao acesso para fins militares?

A resposta parece-nos clara e evidente. Os edifícios deverão ter as infraestruturas de telecomunicações que possam assegurar no presente, ou no futuro, a entrada de redes de novas geração com oferta de serviços até então inimagináveis.

Assim, as novas infraestruturas de telecomunicações integram num único conceito de rede atuais diferentes tipos de redes e serviços. Deste modo, permitirá economia de custos a nível de exploração e manutenção, apresentando ainda como vantagem a convergência de serviços.

Aplicações de segurança e controlo doméstico e empresarial, utilização de videoconferência, plataforma multisserviços assente em IP (Internet Protocol), serviços de assistência médica remota (quer consulta quer operação), serviços informatizados disponibilizados na administração pública, entretenimento online, televisão a 3 dimensões (3D), aulas ministrada em E-learning, são alguns dos exemplos de aplicações e serviços disponibilizados assestes na utilização e exploração das redes de nova geração suportadas pelas infraestruturas de telecomunicações em edifícios.

Afinal o futuro é já amanhã! 
4

ZAP - Resposta do setor industrial

Com a introdução de nova legislação e exigência de novas tecnologias os fabricantes, inevitavelmente, forneceram respostas eficazes na melhoria da concretização das instalações de telecomunicações.

Para cooperar na elaboração artigo convidamos a empresa EFAPEL, fabricante nacional de material elétrico de baixa tensão, a apresentar a solução adotada por esta empresa para a instalação da ZAP.

A EFAPEL apresenta a sua nova gama de tomadas mistas para fazer face aos requisitos mínimos e obrigatórios do enquadramento legislativo emanado pela 2a Edição do Manual ITED.

O produto desenvolvido por esta empresa encontra-se patenteado e permite a instalação, num só ponto, de duas ou três das tecnologias disponíveis: coaxial, par de cobre e fibra ótica, dando assim continuidade à estratégia de permanente investimento em Inovação (ver Figura 3).

Com esta proposta de solução técnica de vanguarda, o fabricante teve a preocupação em reduzir ao máximo o impacto visual causado pela colocação de várias tomadas em linha concentrando, deste modo, as tomadas das diferentes tecnologias numa aplicação mais económica e mais discreta.

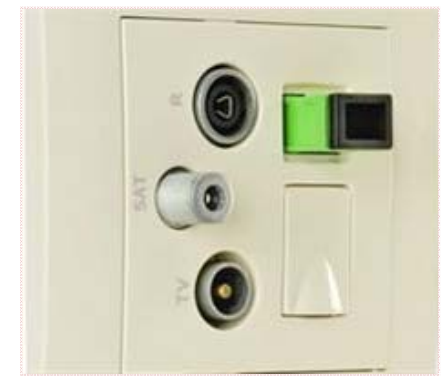

Figura 5 - ZAP - Solução de Tomada Mista (Cortesia EFAPEL)

A Tomada Mista ITED da Figura 5 constitui, além do mais, uma solução económica, pois permite dois aparelhos na Zona de Acesso Privilegiado em vez dos habituais quatro e um aparelho nas demais divisões, em vez de dois.

\section{Conclusões}

Com o presente artigo visou-se evidenciar a evolução da zona de acesso privilegiado ao longo dos recentes anos, no âmbito das infraestruturas de telecomunicações em edifícios.

Foi identificada a evolução da ZAP segundo uma perspetiva legislativa e ainda numa perspetiva tecnológica.

Assim, e dado que a industria se adaptou à mudança de paradigma nas ITED, retratou-se aqui as soluções de vanguarda lançadas por um fabricante nacional - EFAPEL que em apenas duas tomadas sobre o mesmo espelho concentra as características exigidas para o estabelecimento da ZAP.

Assim, com infraestruturas adaptadas às redes de nova geração, com a colocação de equipamentos que, pela sua qualidade, assegurem o melhor beneficio da sua exploração, está, definitivamente, aberta a utilização de serviços e conteúdos inovadores transversais a todas as áreas de negócio e de lazer, com impacto direto na qualidade de trabalho e de vida das pessoas.

O desenvolvimento social e económico da pais passa por inúmeros setores de atividade e, seguramente, o setor das infraestruturas de telecomunicações em edifícios é um deles.

\section{Referências}

[1] Manual ITED - Prescrições e Especificações Técnicas das Infraestruturas de Telecomunicações em Edifícios, 1ạ Edição, ANACOM, Julho 2004.

[2] Manual ITED - Prescrições e Especificações Técnicas das Infraestruturas de Telecomunicações em Edifícios, 2a Edição, ANACOM, Novembro 2009.

[3] Decreto-Lei 59/2000 de 19 de Abril de 2004.

[4] Decreto-Lei 123/2009 de 21 de Maio de 2009.

[5] Decreto-Lei 258/2009 de 25 de Setembro de 2009.

[6] Catálogo Geral da EFAPEL Soluções Elétricas, http://www.efapel.pt/fotos/editor2/catalogo2011/pt/swf/cat pt.html Consultado em Junho de 2012 